\title{
LA MÚSICA COMO FILOSOFÍA EN NIETZSCHE Y DELEUZE. UNA OPERACIÓN DE PLEGADO
}

\author{
Carlos Roldán López \\ Universidad Rey Juan Carlos \\ parresiastes77@hotmail.com
}

\section{Resumen}

Hay en Nietzsche una fusión entre arte y filosofía, al punto en que llega a afirmar que no hay más filósofo que el artista. La filosofía misma se entiende como arte dentro de un esquema general de estetización que el filósofo alemán acomete en la parte final de su pensamiento. Este trabajo presenta un continuum entre el lugar de la música dentro del pensamiento de Nietzsche y el uso que a su vez Gilles Deleuze realiza de la disciplina musical en tanto que creadora de conceptos. En ambos casos no hay una filosofía de la música sino un uso filosófico de la música en la tarea de creación de nuevos conceptos que permiten "componer» filosofía «como si fuera música».

Palabras clave: música, filosofía, creación, estetización, plegado.

\section{MUSIC AS PHILOSOPHY IN NIETZSCHE AND DELEUZE. A FOLDING OPERATION}

\section{Abstract}

We already know that in Nietzsche there is a fusion between art and philosophy, in which philosophy itself is understood as art within a general scheme of aestheticization that the German philosopher undertakes in the final part of his thought. This work presents a continuum between the place of music within Nietzsche's thought and the use that Gilles Deleuze in turn makes of the musical discipline as a creator of concepts. In both cases there is no philosophy of music but a philosophical use of music in the task of creating new concepts that allow "composing" philosophy "as if it were music".

KEYwORDs: music, philosophy, creation, estetization. folding. 
Sin duda, una de las artes que más directamente se relacionan con la filosofía nietzscheana, y con su concepción estética del mundo y la noción de cultivo de sí como obra de arte, es la música. Las reflexiones e indagaciones en torno a lo musical acompañan toda la obra del autor, desde sus primeras aproximaciones relacionadas con el elogio a Wagner hasta sus últimos escritos. Es por eso por lo que consideramos necesario recorrer el lugar que la música ha tenido en su producción, partiendo de sus inicios. En la perspectiva del primer Nietzsche, el consuelo metafísico del arte a través de la apariencia se inscribe en una metafísica de artista que intenta desentrañar el origen doble de la tragedia griega para reinstalarla como el espejo musical en el cual debe mirarse su Alemania contemporánea.

En efecto, El nacimiento de la tragedia se propone indagar el origen y los efectos de la cópula divina de Apolo y Dionisos. La tragedia ática, resultado de esta unión estética divina, representa el modelo estético por excelencia, una estética de cuño romántico que se pronuncia a favor de la superioridad de la forma intuitiva por sobre la del lenguaje. En efecto, se opera aquí una reinterpretación original de Apolo y Dionisos como siendo los instintos artísticos de la naturaleza al igual que en la tragedia: estos expresan, del lado dionisíaco, el dolor primordial de la individuación y, al mismo tiempo, una experiencia transfiguradora apolínea que restituye la calma original a partir de la bella apariencia.

Mucho habremos ganado para la ciencia estética cuando hayamos llegado no sólo al discernimiento lógico, sino a la seguridad inmediata de la intuición de que el desarrollo continuado del arte está ligado a la duplicidad de lo apolíneo y lo dionisíaco: de forma similar a como la generación depende de la dualidad de sexos, en lucha permanente y en reconciliación que sólo se produce periódicamentee.

El devenir conflictivo y contradictorio de esta alianza fatal constituye las condiciones de posibilidad para que el hombre viva en carne viva los movimientos de la voluntad y que de esa manera se comprenda a sí mismo. La música es el lenguaje de esta manifestación potente de la naturaleza que constituye el coro y el mito trágico. Es básicamente en este aspecto que la música se coloca como expresión suprema del mundo intuitivo, su capacidad expresiva inmediata y aconceptual nos hace conocer en forma directa la esencia del mundo:

La música expresa, más que cualquier otro arte, la realidad de la voluntad de poder, ella es aun trágica y melancólica, el fondo de toda vida, pero también un «estimulante de la vida», incitación seductora a la vida. Se comprende así por qué El nacimiento de la tragedia está subtitulada "A partir del espíritu de la música»².

${ }_{1}$ Nietzsche, F. El nacimiento de la tragedia, Madrid, Alianza, 2001, p. 40 (en adelante GT).

2 Blondel, E. «Nietzsche y la música», Magazine Littéraire, 383 (2000), pp. 44-45. 
En efecto, como vemos en la lectura de Nietzsche que hace Blondel lo que el arte consuela es esa herida del individuo cuya imperfección no le permite expresar, ese eterno desconocer lo esencial, esa desintegración de la vida civilizada:

El efecto más inmediato de la tragedia dionisíaca es que el Estado y la sociedad y, en general, los abismos que separan a un hombre de otro dejan paso a un prepotente sentimiento de unidad, que retrotrae todas las cosas al corazón de la naturaleza. El consuelo metafísico -que, como yo insinúo ya aquí deja en nosotros toda verdadera tragedia- de que en el fondo de las cosas, y pese a toda la mudanza de las apariencias, la vida es indestructiblemente poderosa y placentera, ese consuelo aparece con corpórea evidencia como coro de sátiros, como coro de seres naturales que viven inextinguiblemente por detrás de toda civilización y que, a pesar de todo el cambio de las generaciones y de la historia de los pueblos, permanecen eternamente los mismos ${ }^{3}$.

Gilles Deleuze, que también se ocupó de la lectura musical en Nietzsche como paso previo a su propio uso filosófico de la música, afirma que esta íntima relación que Nietzsche plantea entre la música y la vida debe comprenderse como una revalorización de la experiencia intuitiva, de un elogio a la actividad de sentir como afectividad melódico-rítmica que explica la vida y la comprende. Cuando dice que la música de Bizet es mejor que la de Wagner, quiere decir que en la música de Bizet hay algo que despunta y que será muy bien retomado por Ravel enseguida, y ese algo es la liberación de velocidades y lentitudes musicales, es decir, lo que se ha llamado, siguiendo a Boulez, un tiempo no pulsado, en oposición al tiempo pulsado del desarrollo de la forma y la formación del sujeto. No soy una persona, no me trato como una persona, no soy un sujeto, no intento formarme -es lo que le dice a Wagner-, que es la música para Bismarck. No quiere la educación sentimental, lo que le interesa son las ecceidades y las composiciones de intensidades de placer y dolor, se vive como un conjunto de ecceidades ${ }^{4}$.

Esta mezcla de placer-dolor que la música provoca es también el sustrato de la concepción musical nietzscheana; en efecto, la tragedia ática, el modelo más excelso de creación artística, también supone el efecto de la doble influencia apolíneo-dionisíaca, los dos instintos artísticos de la naturaleza. Apolo, el sueño y la agradable apariencia, nos redime y nos cura de los salvajes influjos de la furia embriagante de Dionisos, que hace del dolor primordial, de lo horroroso y lo terrible de la existencia, su razón de ser. En efecto, la apariencia, en tanto reflejo de la contradicción eterna, madre de todas las cosas, aporta la protección y la mesura para que la individualidad pueda seguir viviendo. Sin embargo, la desmesura salvaje de Dionisos, en su contacto con el dolor universal, también nos proporciona un placer glorioso; la gratuidad del devenir impersonal. En la contemplación dionisíaca el devenir impersonal barre las fronteras de la individualidad y nos lleva sin

\footnotetext{
${ }^{3}$ GT $\$ 7$, p. 77.

${ }^{4}$ Deleuze, G. Nietzsche, la música y lo intenso. Revista Entelequia 8(3), p. 243.
} 
mediaciones al sótano inconsciente y oscuro de la vida. Pero si este placer durara mucho nos llevaría al suicidio, simplemente porque consta en el conocimiento de esa voluntad contradictoria que está en el origen de todo el conocimiento de la verdadera tragedia de vivir.

Así, para que esta música fatal no nos liquide, el influjo mesurado y protector de la luz apolínea nos redime en una transfiguración profunda que abre paso a la belleza. Se trata de una transformación mágica. Es por eso por lo que la música es sobre todo un consuelo metafísico. Creemos que la tesis del El nacimiento de la tragedia es que el arte, y especialmente la música, nos hace intuir la unidad de todo lo existente al mismo tiempo que nos da la consideración de la individuación. En este trasfondo pesimista el arte es la alegre esperanza de que pueda romperse el hechizo de la individuación y, de esa manera, nos da el presentimiento de una unidad restablecida.

Bajo la magia de lo dionisiaco no sólo se renueva la alianza entre los humanos: también la naturaleza alienada, hostil o subyugada celebra de nuevo su fiesta de reconciliación con su hijo perdido, el hombre ${ }^{5}$.

Sin embargo, a partir de la presencia de Dionisio, Nietzsche se plantea los problemas de una estética negativa, es decir, de una estética que rescate lo feo, lo disarmónico, como criterios válidos de evaluación del arte. En tanto que la vida comporta un significado trágico no pueden estar ausentes de ella las imágenes de lo desagradable o lo tenebroso. En efecto, el mito trágico nos muestra que lo disarmónico y lo feo son también juegos de la voluntad que juega siempre en la eterna plenitud de su placer. Así, en el final de El nacimiento de la tragedia, lo que está en juego es justificar una estética negativa pero que finalmente aporte un sentido positivo a la contemplación de fenómenos considerados con rechazo. En estos parágrafos se hace hincapié en la irremediable contradicción cómplice de Apolo y Dionisos, se trata de una contradicción inherente al mito trágico. Por eso asistimos, en estas líneas finales, a la exaltación de las pasiones tortuosas, esta representación de lo terrible queda encarnada en la disonancia musical:

El placer que el mito trágico produce tiene idéntica patria que la sensación placentera de la disonancia en la música. Lo dionisíaco con su placer primordial percibido incluso en el dolor, es la matriz común de la música y del mito trágico ${ }^{6}$.

La disonancia interpela a un oír más allá de lo que se está oyendo, es, dice Nietzsche, un aspirar al infinito de un aletazo. Y luego se pregunta: «Si pudiéramos imaginarnos una encarnación de la disonancia - ¿y qué otra cosa es el ser humano?esta disonancia necesitaría para poder vivir, una ilusión magnífica que extendiera

\footnotetext{
5 GT $\$ 7$, p. 78

${ }^{6}$ GT $\$ 24$, pp. $185-189$.
} 
un velo de belleza sobre su esencia propia» ${ }^{7}$. Así, cuando Nietzsche piensa al hombre como encarnación de la disonancia, lo hace con Schopenhauer y en contra de él. En efecto, se critica la función moral del arte. No hay moralidad, sólo como fenómeno estético está justificada la vida. La redención apolínea nunca va a conjurar lo horroroso: lo desagradable se incorpora a la vida como un aspecto más de ella, no como algo a conjurar.

El desafío es articular la noción de disonancia con la de metafísica del arte: si esa articulación se logra, entonces la disonancia musical adquiere un significado milagroso, es la demostración más precisa de la justificación del mundo como fenómeno estético. A su manera, lo que en este texto creemos que se expresa con mayor claridad es que la música puede funcionar como un nuevo modo de encarar la relación con el mundo, aplicable a todos los fenómenos humanos, incluida la reflexión filosófica. En efecto, si la música es un medio privilegiado de comprensión del mundo, leer es ya escuchar porque escuchar es ya pensar. Incluso podría pensarse en una anterioridad del oído musical respecto de los otros sentidos y/o facultades. En efecto, uno resuena antes de razonar. En este sentido, la música no sería solamente una puesta entre paréntesis del tormento de vivir, sino una comprensión más aguda del mismo. El pensamiento encuentra en la música una nueva modalidad de expresión. Naturalmente, no se trata de abandonar la filosofía o su historia, sino de dar fin a una manera metafísica de pensar, aquella que ha sostenido toda la tradición filosófica imperante. Si la palabra pesa y entonces detiene el devenir del mundo, si cristaliza lo existente en valoraciones estáticas, la música es conjugación en presente y, por ello, imposible de infección moral.

Es en este punto de la filosofía nietzscheana donde puede comprenderse de manera cabal la importancia de Wagner en la producción de este filósofo. En palabras de Varela:

Música, eso es lo que Nietzsche quiere escuchar cuando escribe filosofía, palabras que se articulen melódicamente y no en dirección a una verdad. En este registro, sólo Wagner es la música: ninguna partitura lo acerca tanto a su filosofía como las obras de su maestro. Nietzsche es su traducción literaria, su fundamento y también su continuación. Lo que le brinda la cosmología wagneriana no es un contenido, contra el que descarga su dinamita una y otra vez, sino un lenguaje posible para la construcción de su pensamiento ${ }^{8}$.

Siguiendo a Mónica Cragnolini', es posible sostener que la obra de Nietzsche se inicia como monumento a Wagner, se forja como crítica a los postulados presentes en la metafísica wagneriana, y termina como repulsa decidida y cabal a

7 GT $\$ 25$, pp. 190-191.

${ }^{8}$ Varela, G. La filosofía y su doble. Nietzsche y la música, Buenos Aires, Libros del Zorzal, 2008, p. 78.

${ }^{9}$ Cragnolini, M. «Música y filosofía en el pensamiento nietzscheano: sobre entrecruzamientos y tensiones», en AA.VV. Nietzsche actual e inactual. Proyecciones en el pensamiento contemporáneo, Universidad de Buenos Aires, 1994. 
su antiguo maestro. De acuerdo con esta interpretación, Wagner es el símbolo de muchas cosas que van más allá de la música: constituye también la encarnación de toda la metafísica logocéntrica y representativa. Por este motivo, la crítica nietzscheana a Wagner puede ser entendida como una crítica al modelo representacionista en la filosofía, y el desprecio de esta música es también el rechazo de los sistemas que, intentando expresar grandes totalidades, retuercen y fuerzan al lenguaje en busca de la expresión perdida:

Wagner es cada vez más lo que hay que aborrecer, el punto sobre el que se desata la tormenta; su pensamiento es la bajeza que Nietzsche quiere abandonar, la que obliga al espíritu a disolverse fuera de sí; es la experiencia de la debilidad, del sometimiento ${ }^{10}$.

No obstante, más allá de la gradual separación y la feroz crítica que coronará la relación entre Nietzsche y Wagner (que había sido iniciada a partir de la más profunda adoración), de todos modos es imposible negar la influencia del músico en la producción nietzscheana. La música wagneriana abre por primera vez en Nietzsche la exploración de nuevos modos de expresión que trasciendan los límites del lenguaje de la filosofía tradicional, acotado a la búsqueda de la verdad en términos estáticos, carentes de vida:

La relación con Wagner le permite a Nietzsche tomar dimensión de su propia carencia y de la necesidad de tener que forzar a la filosofía a tomar otra dirección. La palabra está acabada, ni siquiera la metáfora puede conducir por fuera de la necesidad de verdad a la que ella misma direcciona. El lenguaje angosto, cierra todo sensualismo, genera ilusiones de verdad en cabezas sin relieve. La música, en cambio, abre, exige un espíritu noble, aristocrático, lejos del intelectualismo que hace del pensamiento una roca pesada ${ }^{11}$.

Así, siguiendo a Varela, es posible decir que si bien en los primeros años de su filosofía Nietzsche está empapado de una metafísica del artista de corte netamente romántico, posteriormente la matriz de la voluntad como fundamento estético va a ser el sustento, en toda su obra, de un aparato crítico demoledor ${ }^{12}$. A partir de este aparato crítico, la voluntad de verdad es considerada como uno de los posibles efectos de una naturaleza irracional, y entonces la verdad pierde su carácter necesario y se vuelve relativa a una fuerza externa a su propia condición. De este modo, Nietzsche acentúa, por un lado, el carácter moral de esa verdad y su pretensión de disciplinamiento sobre los hombres y, por otro, su origen en un impulso estético. Es decir, Nietzsche define a toda verdad, sea la de la ciencia o de la religión, como

\footnotetext{
${ }^{10}$ Varela, G. La filosofía y su doble. Nietzsche y la música, op. cit., p. 52.

${ }^{11}$ Ibidem, p. 79.

12 Ibidem, p. 107.
} 
creación artística. Esto es lo que ha sido negado por la tradición filosófica, y que la música permite desnudar de manera excepcional:

Y es la música el arte que, como prisma de análisis, permite no sólo apreciar la pobreza del pensamiento moderno, sino también leer a la historia de la filosofía como el desenvolvimiento de una palabra que petrifica. Para Nietzsche, la música es lo obstruido por una forma de pensar, es decir, un principio de liberación que queda sepultado por una filosofía del deber, del cálculo y de una espiritualidad programada ${ }^{13}$.

De este modo, es posible reencontrar en la música un nuevo modelo para el pensamiento, que pueda mantenerlo en movimiento evitando la petrificación propia del mundo conceptual como ha sido concebido por la tradición filosófica imperante:

Así, la música habla, no con conceptos, sino con sonidos. Esto no quiere decir que carezca de significaciones sino que estas son dichas en otro lenguaje, uno que no es el de la razón [...]. La música es la misma voluntad, una fuerza irracional que se hace armonía, melodía y ritmo ${ }^{14}$.

La apropiación de la música como un modelo posible para el pensar filosófico deriva en una concepción de la filosofía muy diferente a la que tradicionalmente ha sido aceptada y defendida. En efecto, con esta reapropiación del lenguaje musical Nietzsche abre las puertas para que muchos autores posmodernos puedan luego replantearse los modos de expresión y la definición misma de la filosofía. La concepción de la filosofía como pensamiento musical no es entonces simplemente una bella fórmula poética. Remite, de manera clara, al carácter inmanente que Nietzsche busca otorgarle al pensar filosófico, y hace referencia a aquellos elementos de su filosofía que serán retomados posteriormente por numerosos filósofos contemporáneos.

¿Cómo es posible que la filosofía sea música? En principio, abandonando la idea de una verdad trascendente, es decir, ya no suponer que el pensamiento filosófico es reproductivo de una realidad en sí, sea esta la del mundo, la del Ser, o la de Dios. Esto hace que los enunciados de un pensar estén desprendidos de la obligación de referirse por fuera de sí mismos. [...]. El fundamento de todo pensar es estético ya que remite a una disposición creadora del hombre, en tanto compone, crea, produce acordes conceptuales que se ordenan a través de una escritura ${ }^{15}$.

No es el objetivo de este trabajo colaborar en modo alguno con una filosofía de la música, ni gestionar las relaciones y tensiones que esta dirección del pensamiento implican, sino más bien profundizar en las consecuencias de un modo de pensar y comprender la filosofía entendida desde una perspectiva musical y ello

13 Ibidem, p. 112.

14 Ibidem.

15 Ibidem, p. 119. 
puede reencontrarse, de manera bastante clara, en el pensamiento de Gilles Deleuze, que es uno de los tantos filósofos contemporáneos que han retomado la teoría nietzscheana y su definición del pensamiento filosófico desde una concepción artística de la creación conceptual.

En su libro ¿Qué es la filosofía? Deleuze define a la filosofía como el arte de crear conceptos. Ahora bien, todo concepto tiene componentes y se define por ellos. Se trata de una multiplicidad, y no de una unidad. El concepto es una cuestión de articulación, de repartición, de intersección. Forma un todo, porque totaliza sus componentes, pero un todo fragmentario. Y además, todo concepto tiene un movimiento, un devenir que atañe a los conceptos que se encuentran en su mismo plano. El concepto es efectivamente, en este sentido, un acto de pensamiento, puesto que el pensamiento opera a velocidad infinita ${ }^{16}$. Como puede verse, esta definición contemporánea de filosofía coincide en muchos puntos con la concepción nietzscheana del pensamiento filosófico definido a partir de la música:

Es la palabra musical del recitado, donde la relación entre los conceptos es sonora, depende de su colocación, de su altura, como en una línea melódica. Por ello el sentido de un concepto no está definido de antemano sino en relación con los otros conceptos con los que opera. Una cadena de conceptos conforma un pensamiento, pero la potencia de este está dada en cuanto sonido, en cuanto pensamiento cantado $^{17}$.

Partiendo de forma declarada de los posicionamientos de Nietzsche sobre la música, Deleuze invierte la dirección del discurso siendo la música la que pasa a ser una indagación filosófica, la música es una filosofía en tanto que música, y esto lo podemos ver a través de su concepto de ritornelo.

El propio ritornelo es el contenido de la música [...]. Nosotros no decimos en modo alguno que el ritornelo sea el origen de la música, o que la música comience con él. El ritornelo sería más bien un medio de impedir, de conjurar la música o prescindir de ella. Pero la música existe porque también existe el ritornelo, porque la música toma, se apodera del ritornelo como contenido en una forma de expresión, porque forma un bloque con él para llevarlo a otro sitio [...]. La música es la operación activa, creadora, que consiste en desterritorializar el ritornelo. Mientras que el ritornelo es esencialmente territorial, territorializante o reterritorializante, la música lo convierte en un contenido desterritorializado para una forma de expresión desterritorializante ${ }^{18}$.

Para Deleuze, la desterritorialización del Ritornelo está asociada bellamente al uso de la música que hacen los pájaros. Y a partir de aquí Deleuze construye el discurso de uso filosófico de la música. En efecto, los pájaros ubican su territorio a

16 Cfr. Deleuze, G. y Guattari, F. ¿Qué es la filosofía?, Barcelona, Anagrama, 1993.

${ }^{17}$ Varela, G. La filosofia y su doble. Nietzsche y la música, op. cit., p. 118.

18 Deleuze, G. Mil mesetas, Barcelona, Anagrama. 
través del canto. Su movimiento está basado en el canto como discurso, su canto repetitivo construye su mundo, los pájaros son artistas en el sentido de que utilizan el concepto de arte en el que insisten tanto Nietzsche como Deleuze, el arte de construcción de posibles: «El arte no es un privilegio del hombre. Messiaen tiene razón cuando dice que muchos pájaros no sólo son virtuosos, sino artistas» ${ }^{19}$. Es claro que Deleuze no está humanizando a los pájaros, sino deshumanizando al hombre. Al igual que Nietzsche, Deleuze coge modelos de la naturaleza y pretende su asunción por parte del hombre. En este caso, siguiendo la estela nietzscheana de adoptar comportamientos extrahumanos, Deleuze entiende la filosofía que nos ofrece la música como una operación de desterritorialización del hombre que debe aprender a cantar para volar.

En este punto, es necesario traer aquí las continuas referencias que hace Deleuze en sus escritos al niño que muere, que muere porque a través del canto deviene música, la desaparición transmutada en pieza musical ya operada cuando el infante opera la desterritorialización del chillido en voz:

El canto se anuda en el tiempo suspendido de la vida, en la fragilidad del aún-no embrionario y la fuga sobre una línea de abolición que nos lleva a la muerte: «El Canto es la repetición idéntica pero distinta, de la vida, repetición que la ordena y la «salva». Sin el Canto que la constrińe, la vida no puede expandirse y se extingue. Así retorna el cisne que convocamos al inicio de este escrito, que canta mejor cuando está por morir, cuando emprende finalmente el camino que lo lleva más allá de su mundo, quizás a su espacio exterior.

Es a partir de aquí cuando podemos entender el sentido que Deleuze atribuye a la música dentro el esquema más general de la actividad liberadora del pensamiento. Dice Deleuze:

No se trata de someter la filosofía a la música ni tampoco de lo contrario. Se trata, una vez más, de una operación de plegado: "pli selon pli», como hace Boulez con Mallarme. Movimiento de plegado análogo con Boulez y Cage. Se trata pues de colocarse en la línea de fuga musical, en el espacio liso, que es el espacio de las mutaciones ${ }^{20}$.

Es a partir de esta operación de plegado cuando podemos entender la función que la música opera en el pensamiento y en la vida, puesto que no es concebida sino como una tarea de composición de bloques sonoros que «condensan intensidad, vibración y resonancia del pensamiento; hace del pensamiento una Máquina de Guerra ${ }^{21}$. Entendemos que Deleuze realiza el destapado de oídos que Nietzsche reclama y que sitúa a la música más allá del bien y del mal conectándola directamente con la

19 Cfr. Sauvagnargues, A. Deleuze. Del animal al arte, Buenos Aires, Amorrortu, 2006.

${ }^{20}$ RANGeL, S. Ideas musicales, preludio para una filosofía de la música, Instituto de Estudios Críticos.

${ }^{21}$ Ibidem. 
operación de acabar con una forma metafísica de pensar y es que, obviamente, no nos referimos ya a la música que Platón describía en parte como educación sentimental, rechazada por Deleuze como hemos visto al principio de este trabajo. Los bloques sonoros son efectivamente irreductibles a la infección moral y remiten a la idea de lo sonoro como habla, como lenguaje sonoro entendido como fuerza irracional comprometido con la tarea desterritorializante. Como vemos, lo que para Nietzsche era una identificación y una reapropiación del lenguaje musical para afectar al pensamiento, nietzscheanamente, Deleuze lo lleva hacia la operación de plegado en el que la música construye mundos, construye posibles.

Recibido: noviembre de 2018. Aceptado: enero de 2019 